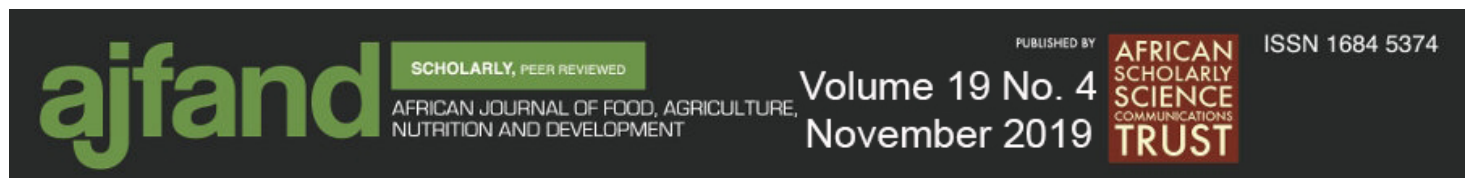

\title{
OCCURRENCE OF MYCOTOXINS \\ IN FARM-STORED WHEAT IN ETHIOPIA
}

Worku AF ${ }^{1}$, Merkuz A ${ }^{3}$, Kalsa $K_{K}^{4}$, Tenagashaw $\mathrm{MW}^{2^{*}}$ and NG Habtu ${ }^{1}$

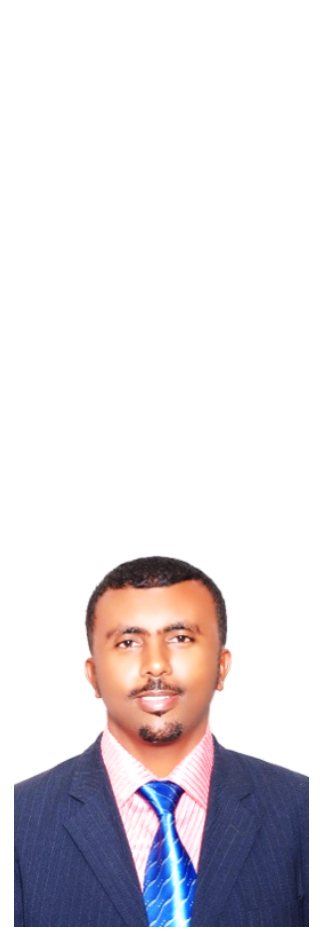

Tenagashaw M

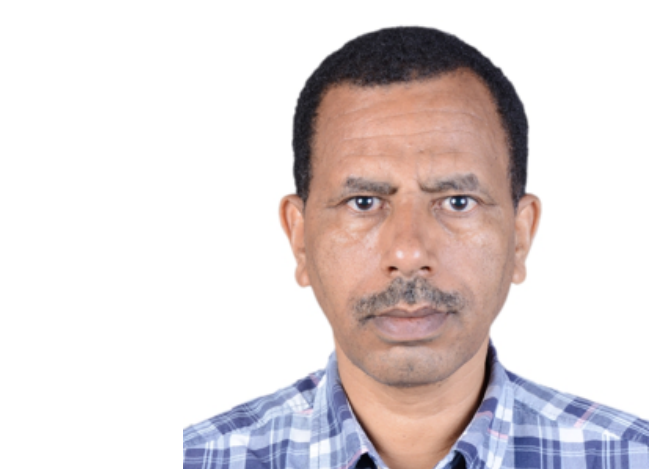

Worku Admasu Fanta

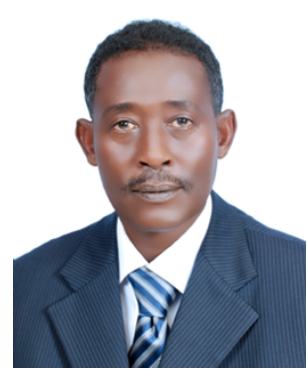

Merkuz A

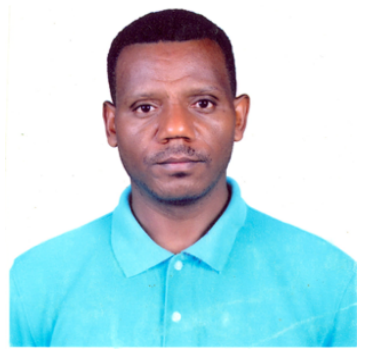

Kalsa KK

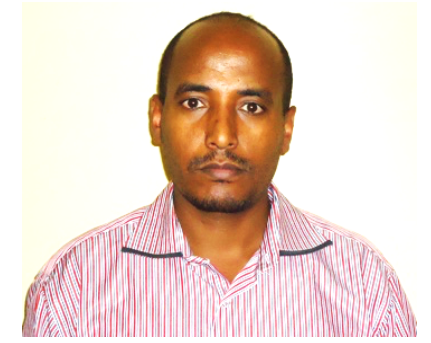

Habtu NG

*Corresponding author email: mesfinwogayehu@gmail.com

${ }^{1}$ Department of Postharvest Technology, Technology Institute, Bahir Dar University, P.O. Box 26, Bahir Dar, Ethiopia

${ }^{2}$ Department of Applied Human Nutrition, Technology Institute, Bahir Dar University, P.O. Box 26, Bahir Dar, Ethiopia.

${ }^{3}$ Department of Plant Science, College of Agriculture and Environmental Sciences, Bahir Dar University, P.O. Box 5501, Bahir Dar, Ethiopia.

${ }^{4}$ Department of Seed Technology, Asella Research Centre, Ethiopian Institute of Agricultural Research, P.O. Box 489, Asella, Ethiopia 


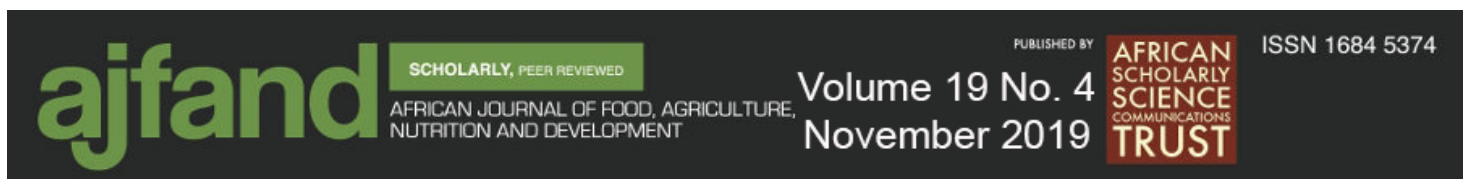

ABSTRACT

In recent years, food safety has become an integral component of ensuring food security. Mycotoxin development in staple cereals is a principal threat to realizing food safety in developing countries. With the objective to investigate incidences and levels of mycotoxins in farm-stored wheat from major growing districts of Ethiopia, a study was conducted based on 179 samples collected from six districts: Wenberma, Merawi, Ofla, Hetosa, Gedeb, and Lemo. Total aflatoxins (AFT), Ochratoxin A (OTA), total fumonisins (FUM), and deoxynivalenol (DON) were determined using lateral flow immunoassays. Results indicated that the most common method used by farmers for storing wheat was polypropylene bag $(92.2 \%, \mathrm{n}=179)$. Incidences of AFT, OTA, FUM, and DON were $60.3 \%, 20.1 \%, 16.2 \%$, and $9.5 \%$, respectively. Levels in positive samples ranged from $2.5 \mu \mathrm{g} / \mathrm{kg}$ to $16.7 \mu \mathrm{g} / \mathrm{kg}$ for AFT, $2.1 \mu \mathrm{g} / \mathrm{kg}$ to $148.8 \mu \mathrm{g} / \mathrm{kg}$ for OTA, $0.33 \mathrm{mg} / \mathrm{kg}$ to $0.71 \mathrm{mg} / \mathrm{kg}$ for FUM, and $0.35 \mathrm{mg} / \mathrm{kg}$ to $1.14 \mathrm{mg} / \mathrm{kg}$ for DON. Age of wheat grains after harvest had a significant effect $(\mathrm{P}<0.05)$ on the incidence of AFT. Less AFT incidence was observed in samples aged 3 months than in the older ones. None of the wheat samples exceeded the $20 \mu \mathrm{g} / \mathrm{kg}$ maximum level set for AFT by the FDA of the USA. However, 50.8\% $(n=179)$ exceeded the EU maximum level set at $4 \mu \mathrm{g} / \mathrm{kg}$ for AFT in cereals. Ochratoxin A (OTA) levels in $4.5 \%(n=179)$ of wheat samples exceeded the $5 \mu \mathrm{g} / \mathrm{kg}$ maximum level set by the EU for unprocessed cereals. Deoxynivalenol levels in $3.4 \%(n=179)$ of wheat samples exceeded the $0.75 \mathrm{mg} / \mathrm{kg}$ maximum level set by the EU. Besides, co-occurrences of mycotoxins were observed, and the binary co-occurrences of AFT-OTA $(7.8 \%, \mathrm{n}=179)$ and AFT-FUM $(7.3 \%$, $\mathrm{n}=179$ ) were the dominant ones. The result of the present investigation underscores the occurrence of mycotoxins in farm-stored wheat in Ethiopia. Appropriate measures need to be taken to enable farmers to use improved grain storage technologies such as the use of multi-layer hermetic bags, which are capable of protecting wheat from physical and biological factors that lead to mycotoxin formation.

Key words: Farm-stored wheat, Mycotoxin co-occurrence, Ethiopia, Grain age, Water activity 


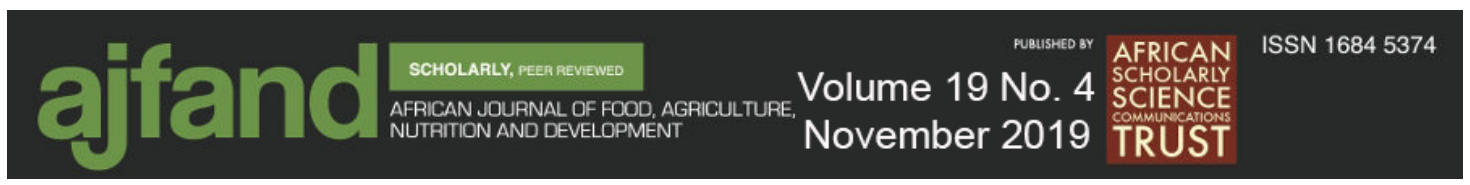

\section{INTRODUCTION}

Wheat accounts for $13.8 \%$ of African cereal production and Ethiopia ranks first in wheat production among the countries of sub-Saharan Africa [1] with 4.6 million tons produced on 1.7 million hectares during the major season of 2017/18 [2]. The most consumed food groups in Ethiopia are cereals [3], of which wheat is an important grain to the national food supply. On average, wheat accounts for $287 \mathrm{kcal} / \mathrm{capita} /$ day, second to maize (401 kcal/capita/day) over the period between 2010 and 2013 [4]. The demand for wheat has been rapidly rising [5]. According to the Central Statistical Agency (CSA) [6], most of the annual production was used for home consumption after milling by local stone mills into whole grain flour, and only about $20 \%$ was for sale in the marketing channels. Only part of the $20 \%$ of wheat sold is further processed into refined flour using industrial roller milling operations. This suggests that most of the wheat production is stored on-farm for household food supply until the next successful harvest and milling to whole grain flour is the dominant primary processing method.

On-farm grain storage methods in Ethiopia represent poor barriers against environmental and biological deterioration agents, and grains are stored mainly inside the house in porous bags [7]. Dried commodities stored in woven porous bags can gain moisture from an environment of high relative humidity, enabling insect infestation and fungal infections [8].

Traditional storage methods often lead to mould infection and contamination by mycotoxins and toxic secondary metabolites [9] produced by various species belonging to three main genera of fungi (Aspergillus spp., Fusarium spp., and Penicillium spp.) [10]. In Ethiopia, grains are stored in traditional structures such as gotera, gota, polypropylene and jute bags. Gotera is an outdoor storage structure made from mud or cow dung plastered basketwork covered with thatched roofing and raised off the ground with stones or wooden platform. Gota is an indoor grain storage bin made of mud plaster mixed with teff straw [7] to render the storage structure durability by cementing the mud plaster together. Based on extensive analytical results and detailed information on the distribution of fungi in staple crops, total aflatoxins (AFT), ochratoxin A (OTA), fumonisin (FUM), and deoxynivalenol (DON) have gained global importance [11].

Few reports in the past indicated that wheat from sub-Saharan Africa was infected by the mycotoxigenic fungi and can be contaminated with associated mycotoxins $[12,13]$. Although the occurrence of Fusarium toxins in wheat from temperate climate is well documented, little has been done in that respect in tropical regions, hence limited occurrence data is available [14].

Therefore, the objective of this study was to investigate incidences, levels, and cooccurrences of AFT, OTA, FUM, and DON in farm-stored wheat samples collected from high wheat-producing areas of Ethiopia. The result will serve as an input to mycotoxin exposure assessment studies in the country. It will also play a crucial role as evidence to encourage concerned stakeholders to devise an appropriate mechanism to protect the grain from mycotoxin contamination during farm storage. 


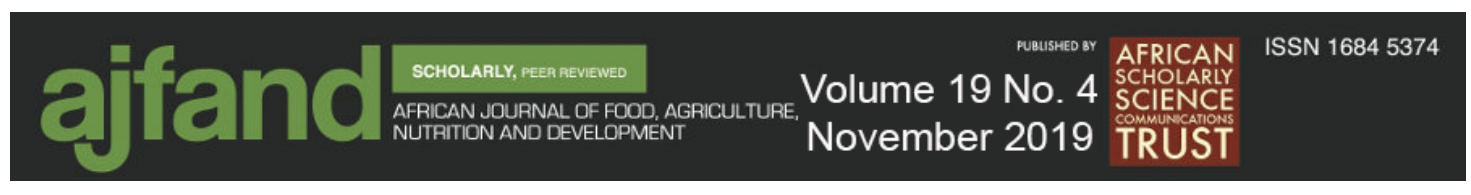

\section{MATERIALS AND METHODS}

\section{Description of study areas}

Six wheat-growing districts from four regions of the country, namely Amhara, Oromiya, Southern Nations Nationalities and Peoples Region (SNNP), and Tigray were included in the survey (Figure 1). The six districts were Wenberma, Merawi, Ofla, Hetosa, Gedeb, and Lemo. The latitude, longitude, and altitude range of the study sites were $7.093^{\circ}$ to $12.553^{\circ}, 36.905^{\circ}$ to $39.491^{\circ}$, and $2046 \mathrm{~m}$ to $2468 \mathrm{~m}$, respectively.

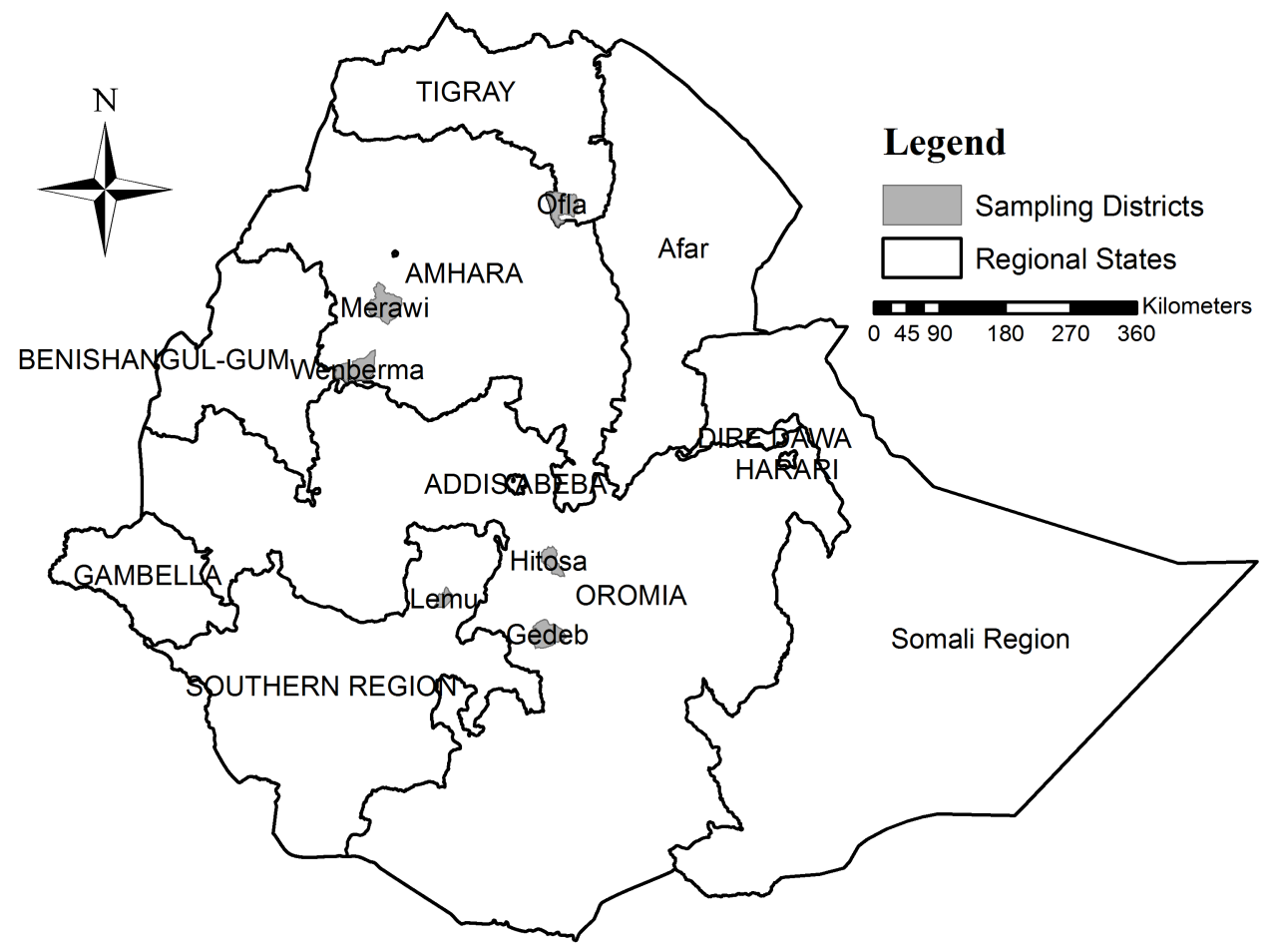

Figure 1: Map of Ethiopia showing wheat sampling districts

\section{Sampling}

A total of 179 farm stores in the six wheat-growing districts were selected to collect wheat samples in June 2016. A village with high wheat production was identified through discussions with district-level crop production experts. A total of 30 farmers from each village who grow wheat were randomly selected. Taking 30 samples per district was justified based on the central limit property [15]. Every third household within each village was chosen as a sampling unit. In case of absence of an adult person in a household, the next household was used as a sampling unit. When storage containers were bags, as many bags as possible were sampled depending on the number of available bags [16]. In traditional gota and gotera, however, samples were taken from the top, mid and bottom of the container and then thoroughly mixed to form a primary sample. Each sample collected was approximately $2 \mathrm{~kg}$. At the time of sampling, information on grain age (duration from harvest to sampling) was recorded. Each primary sample was reduced to $1 \mathrm{~kg}$ size by subdividing it through coning and 


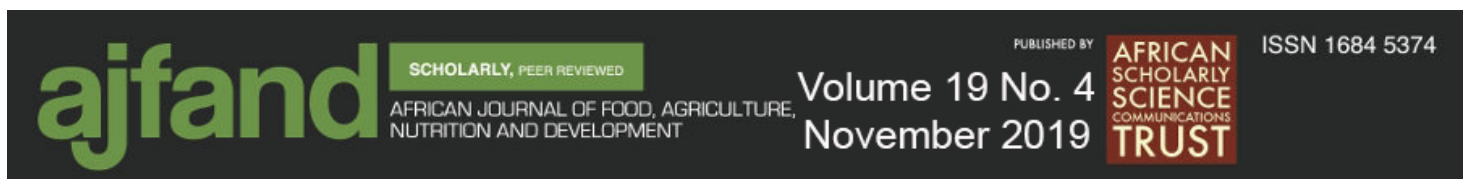

quartering. Samples were packed in polypropylene bags and transported immediately to the food safety laboratory of Bahir Dar University. Samples were then stored in a refrigerator at $4^{\circ} \mathrm{C}$ until used for analysis.

\section{Water activity}

Water activity was measured using the chilled mirror dew point method [17] using an Aqualab 4TE (Decagon Devices, Inc Pullman, Washington, USA) following the manufacturer's instructions. The measurements were conducted at $25^{\circ} \mathrm{C}$ on randomly taken samples of about 100 wheat kernels from each sample collected in each district. Each $1 \mathrm{~kg}$ wheat sample was reduced by coning and quartering method [16] to approximately $125 \mathrm{~g}$ sub-sample from which the 100 kernels were taken. Measurements were taken on the same date as sampling of wheat was done.

\section{Mycotoxin Analysis}

A representative $500 \mathrm{~g}$ of each sample was ground to flour using a cyclone sample mill (Model: 3010-019, UDY Corporation, Fort Collins, Colorado, USA). A 75\% portion of the ground sample passed through a 20 -mesh screen, indicating that the particle size requirement of the whole ground sample was met. The whole grain flour was then thoroughly mixed and kept sealed in a labelled polypropylene bag and stored in a refrigerator at $4^{\circ} \mathrm{C}$ until needed for mycotoxin analysis.

The levels of AFT, OTA, FUM, and DON in wheat samples were quantified using the lateral flow immunoassay principle on indirect competitive immunoassay format according to the protocols of the manufacturer provided in the respective kit (Charm Sciences, Lawrence, Massachusetts, USA). Prior to analysis, the Charm reader (model LF-ROSA-EZ-M) performance was tested daily using the calibration strips provided by the manufacturer. Additionally, the test strip performance was verified weekly by running a negative control and a positive control supplied in each kit by the manufacturer. Further steps were continued only when the kit and reader performances were within specified limits indicating readiness for use for the analysis. Before starting the mycotoxin extraction process, the Charm EZ-M reader was switched on, and the incubator temperature read $45 \pm 1^{\circ} \mathrm{C}$. Besides, it was ensured that all reagents and the kit components were at room temperature $\left(18-30^{\circ} \mathrm{C}\right)$. Next, $50 \mathrm{~g}$ ground wheat sub-sample was weighed into a whirl-pack bag and extracted with $100 \mathrm{ml} 70 \%$ methanol (for AFT, OTA, and FUM) or $250 \mathrm{ml}$ distilled water (for DON) by vigorously shaking for $1 \mathrm{~min}$. About $1.5 \mathrm{ml}$ of the extract was centrifuged in a microcentrifuge tube for $10 \mathrm{sec}$ to get a supernatant from which $100 \mu \mathrm{l}(50 \mu \mathrm{l}$ for DON) was pipetted into a new micro-centrifuge tube containing $1.0 \mathrm{ml}$ dilution buffer of the respective mycotoxin, capped and mixed by inverting up and down five times. The diluted extract was further filtered through a Minisart RC15 syringe into a new microcentrifuge tube to obtain a diluted-filtered extract that was ready for analysis. Next, the Charm EZ-M reader was set up for a test by selecting the mycotoxin of interest and the test type, followed by selecting wheat from a list of grains displayed by pressing the commodity button. Finally, the appropriate dilution (matrix) was selected (Table 1).

A test strip belonging to a specific mycotoxin was then inserted into the slot of the Charm EZ-M built-in incubator. After exposing the sample compartment of the test 


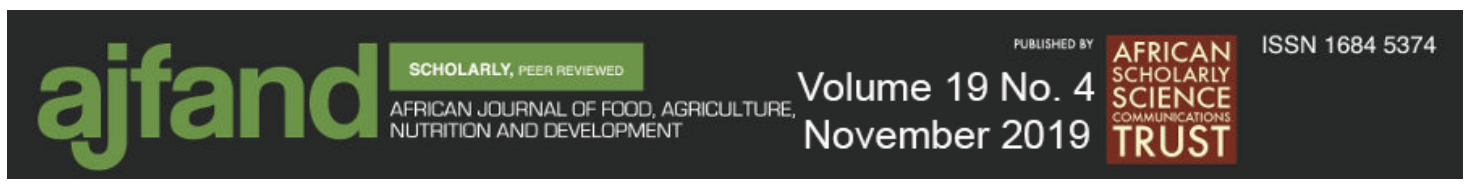

strip by peeling the tape, $300 \mu \mathrm{l}$ of the diluted-filtered extract was pipetted into it, followed by incubating for $5 \mathrm{~min}$ (AFT and FUM), 10 min (OTA), and 2 min (DON). The concentration of the mycotoxin was then displayed at the end of the test. Total aflatoxins (AFT) and OTA are expressed in parts per billion (ppb) or microgram per kilogram $(\mu \mathrm{g} / \mathrm{kg})$. However, FUM and DON are expressed in parts per million (ppm) or milligram per kilogram $(\mathrm{mg} / \mathrm{kg})$.

Readings below the limits of detection (LOD) were recorded as zero [18]. Readings between LOD and the lower limit of quantification (LOQ) were recorded as LOQ/2 [19]. For readings exceeding the higher limit of quantification of the filtered diluted extract (matrix 00), the filtered diluted extract was further diluted to the $2^{\text {nd }}$ diluted extract by pipetting $300 \mu \mathrm{L}$ of the filtered diluted extract to a micro-centrifuge tube containing $1.0 \mathrm{ml}$ of dilution buffer of the respective mycotoxin. For the reading of the mycotoxin in the $2^{\text {nd }}$ diluted extract similar procedure was followed except the matrix 01 was selected in the test set up.

\section{Data Analysis}

Mycotoxin occurrence data were analyzed using descriptive statistics such as frequency and central tendency measures. One-way analysis of variance (ANOVA) was employed to detect differences among samples across studied districts or different grain ages after harvest. Where ANOVA was significant $(\mathrm{P}<0.05)$, treatment means were compared using Tukey's Honest Significance (HSD) Test at 5\% level of significance. Associations between the frequencies of mycotoxin positive samples and district or grain age were carried out using Fisher's exact test [20]. All analyses were performed using R software version 3.5.0 [21].

\section{RESULTS AND DISCUSSION}

\section{Storage methods, grain age, and variety}

The most common method used by farmers for storing wheat was polypropylene bag $(92.2 \%, \mathrm{n}=179)$ followed by gota $(6.1 \%, \mathrm{n}=179)$. Gotera, metal silo, and plastic drum were each used by one $(0.6 \%)$ out of the 179 farmers' stores. The results are in good agreement with a report by Hengsdijk and De Boer [7], who indicated that most cereals in Ethiopia are stored in bags that are placed inside the house. Such storage methods cannot provide good protection against external factors, regardless of initial grain quality. These porous bags allow the grains to exchange moisture and air with the environment and provide access to insects to develop inside [8]. Insect activity and a high relative humidity environment permit dry grains to re-hydrate, thereby increasing the risk of mould growth and mycotoxin development. In developing countries, storage methods generally provide poor protection, and hence losses of grains at this stage of the supply chain are considered most critical [22].

Grain ages (durations from harvest to sampling) were three months (12.8\%), seven months $(48.8 \%)$, and eight months $(41.3 \%)(n=179)$. Of the 179 wheat samples, the most frequent varieties were Kubsa $(28.5 \%)$ and Kakaba $(26.8 \%)$ followed by Danda'a $(11.2 \%)$, Kingbird (7.3\%), Digelu (7.3\%), Hidasie (7.3\%), Local (3.9\%), Ogolcho (2.8\%), Galama (2.2\%), mixed varieties (2.2\%), and Dashen (0.6\%). 


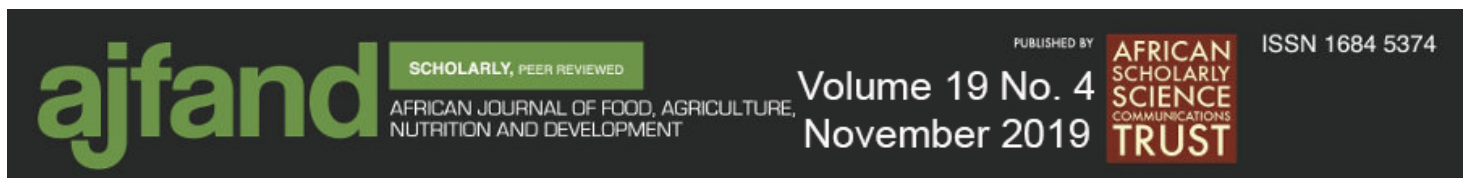

Water activity $\left(\mathbf{a}_{w}\right)$

Water activity $\left(a_{w}\right)$ values of wheat samples across districts and grain ages are shown in Table 2. District and grain age had significant effects on $a_{w}$ of wheat grain samples $(\mathrm{P}<0.05)$. The lowest mean $\mathrm{a}_{\mathrm{w}}$ was recorded in Merawi district and at the age of three months (Table 2). The result agrees with an earlier report on farm-stored maize collected at ages of six and seven months from five districts of Ethiopia [23]. Those authors highlighted that a higher average $a_{w}$ was exhibited by the seven-month old maize than that exhibited by the six-month old maize. Insect activity and mould growth in stored grain can advance as storage time progresses. The increase in biological activity with storage time results in increased $\mathrm{a}_{\mathrm{w}}$ that might lead to mould growth and mycotoxin development. Differences in $\mathrm{a}_{\mathrm{w}}$ across districts might be attributed to variations in weather condition and relative humidity and pest infestation levels of stored grains. Farmers' practices, such as harvesting, drying, and storage can influence stored grain's pest infestation and rehydration levels, which can vary from district to district.

\section{Incidences and levels of mycotoxins}

The incidences and levels of the analyzed mycotoxins are shown in Table 3 . The overall level of AFT in positive samples ranged from $2.5 \mu \mathrm{g} / \mathrm{kg}$ to $16.7 \mu \mathrm{g} / \mathrm{kg}$. While all samples had AFT levels below the $20 \mu \mathrm{g} / \mathrm{kg}$ maximum level set by the Federal Drug Administration (FDA) of the USA [24], 49.2\% $(n=179)$ of samples were below the stricter $4 \mu \mathrm{g} / \mathrm{kg}$ maximum level set by the European Union (EU) [25]. Proportions of positive samples across grain ages and districts are shown in Table 4 and Table 5, respectively. Fisher's exact test revealed that the proportion of AFT-positive samples were significantly $(p<0.05)$ influenced by grain age (Table 4$)$ and district (Table 5).

No significant effect of grain age (Table 4) or district (Table 5) was observed on the proportion of OTA-positive samples. About $4.5 \%$ of the total samples $(n=179)$ or $22.2 \%$ of OTA-positive samples $(\mathrm{n}=36)$ exceeded the $5 \mu \mathrm{g} / \mathrm{kg}$ maximum level set by the EU. A significant $(\mathrm{p}<0.05)$ difference among districts was detected in the proportion of FUM-positive samples (Table 5). However, the proportion of FUMpositive samples was not significantly influenced $(\mathrm{p}>0.05)$ by the age of grain (Table 4). Incidence of DON was the least of all the mycotoxins' frequencies, and $3.4 \%$ of total samples $(n=179)$ or $35.3 \%$ of DON positive samples $(n=17)$ exceeded the EU maximum level $(0.75 \mathrm{mg} / \mathrm{kg})$ set for cereals intended for direct human consumption. The proportion of DON positive samples was not significantly influenced by grain age (Table 4) or district (Table 5) at a 5\% significance level.

The incidence of AFT-positive samples $(60.3 \%)$ was the highest of the investigated mycotoxins in the wheat samples, followed by OTA (20.1\%). All the AFT-positive samples had levels below the FDA maximum level set for human food $(20 \mu \mathrm{g} / \mathrm{kg})$. On the other hand, only $15.7 \%$ of the AFT-positive samples $(n=108)$ or $49.2 \%$ of total samples $(\mathrm{n}=179)$ had AFT levels below the EU maximum level $(4 \mu \mathrm{g} / \mathrm{kg})$. However, the stricter EU maximum level assumes that Aflatoxin contamination of grains is unavoidable and the set maximum can be reasonably achieved by following good agricultural practice [25], a practice that is non-existent in the smallholder-based production system of Ethiopia. Limited information exists on AFT contamination in 


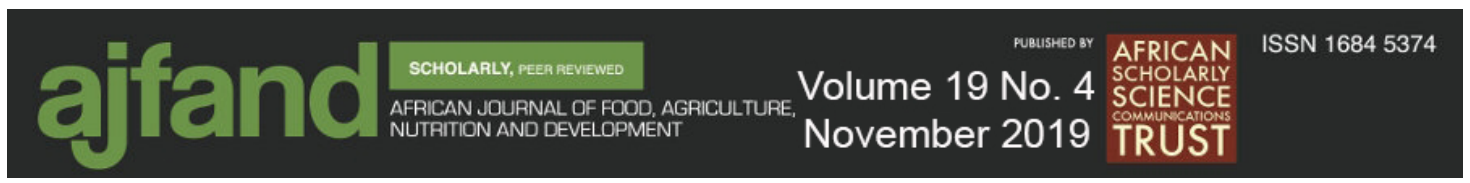

wheat from Ethiopia. Ayalew et al. [13] reported that Aflatoxin $\mathrm{B}_{1}$ incidence in wheat collected from West Shewa (Ethiopia) in 1999 was 4.2\% $(n=120)$ with median, mean and maximum levels among positive samples of $9.5 \mu \mathrm{g} / \mathrm{kg}, 8.7 \mu \mathrm{g} / \mathrm{kg}$, and $12.3 \mu \mathrm{g} / \mathrm{kg}$, respectively. The lower incidence rate of Aflatoxin $\mathrm{B}_{1}$ reported by Ayalew et al. [13] compared to the present investigation could be attributed to seasonal variations, sampling location, or the fact that those authors considered only Aflatoxin $\mathrm{B}_{1}$. Besides, the age of wheat grain samples after harvest might have also contributed to the lower incidence of Aflatoxin $\mathrm{B}_{1}$. Wheat samples used by Ayalew et al. [13] were collected from threshing yards and four to six months later from traditional farm storage structures. This assumption is supported by the result of the present investigation regarding the effect of grain age on AFT incidence (Table 4).

The OTA incidence in the present study (20.1\%) agrees with the 23.4\% OTA incidence $(n=107)$ reported by Ayalew et al. [13]. Those authors also reported that the median, average, and maximum levels of OTA in the positive wheat samples were $14.9 \mu \mathrm{g} / \mathrm{kg}$, $19.6 \mu \mathrm{g} / \mathrm{kg}$, and $66 \mu \mathrm{g} / \mathrm{kg}$, respectively. The OTA concentration level reported by Ayalew et al. [13] is generally higher than that in the present study (Table 3), for some of the reasons discussed above.

The occurrence of Fusarium mycotoxins has been associated with a temperate climate. However, recent trends in climate change seem to have exposed the tropics to the toxins [14]. Sub-Saharan Africa is among regions that are vulnerable to climate change impacts because its agricultural production depends solely on weather and climate [26]. A positive association between drought stress and fumonisin production was reported $[27,28]$. The present survey showed that levels of the FUM-positive samples were generally low (Table 3), and no sample had FUM levels above $1 \mathrm{mg} / \mathrm{kg}$. A previous report on FUM contamination in wheat samples $(n=15)$ collected from West Shewa, Ethiopia, indicated that no FUM was detected [13]. However, Mashinini and Dutton [12] highlighted that FUM was detected in $4 \%(n=84)$ wheat samples from South Africa with levels ranging between $1 \mathrm{mg} / \mathrm{kg}$ to $2 \mathrm{mg} / \mathrm{kg}$.

\section{Co-occurrence of mycotoxins}

None of the analyzed mycotoxins tested for was detected in $24.6 \%(n=179)$ of the samples, while only one of them was detected in $50.3 \%(n=179)$ of all the wheat samples. However, 19.6\% $(\mathrm{n}=179)$ and $5.6 \%(\mathrm{n}=179)$ of samples were contaminated with two and three mycotoxins, respectively (Figure 2). The co-occurrence of AFTOTA and AFT-FUM were the dominant ones observed in $7.8 \%$ and $7.3 \%$ of total samples $(\mathrm{n}=179)$, respectively. Incidences of AFT-OTA and AFT-FUM co-occurrences are among the most prevalent mycotoxin co-occurrences reported in the literature [29]. In the AFT-OTA co-contaminated samples, AFT ranged between $2.5 \mu \mathrm{g} / \mathrm{kg}$ and 12.8 $\mu \mathrm{g} / \mathrm{kg}$ (mean=8.6 $\mu \mathrm{g} / \mathrm{kg}$ ) whereas OTA levels ranged between $2.1 \mu \mathrm{g} / \mathrm{kg}$ and 132.2 $\mu \mathrm{g} / \mathrm{kg}$ (median=3.7 $\mu \mathrm{g} / \mathrm{kg}$ ). In the AFT-FUM co-contaminated samples, AFT ranged from $2.5 \mu \mathrm{g} / \mathrm{kg}$ to $10.3 \mu \mathrm{g} / \mathrm{kg}$ (mean= $6.6 \mu \mathrm{g} / \mathrm{kg}$ ) while FUM ranged from $0.33 \mathrm{mg} / \mathrm{kg}$ to $0.71 \mathrm{mg} / \mathrm{kg}$ (mean= $0.44 \mathrm{mg} / \mathrm{kg})$. 


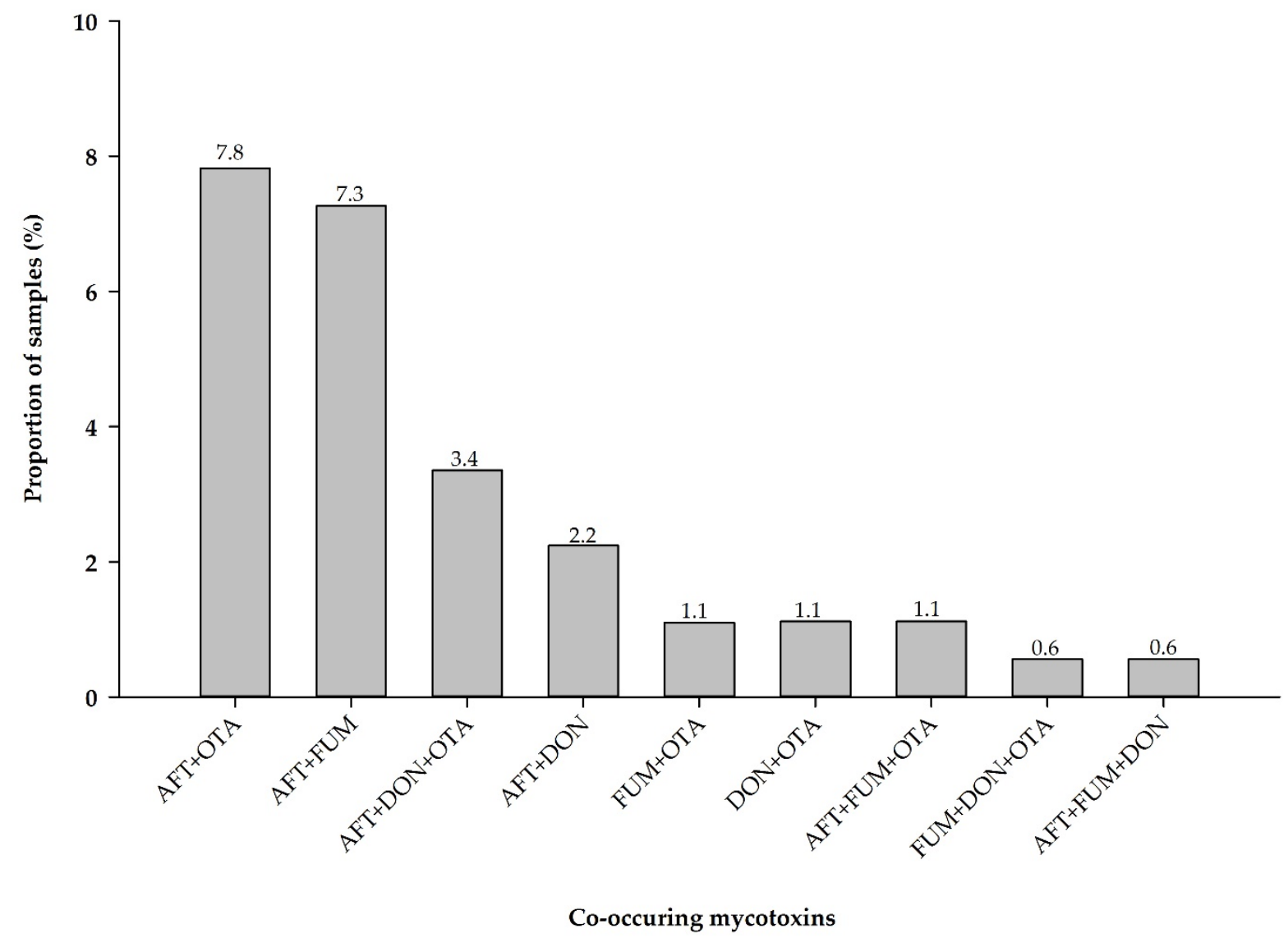

Figure2: Co-occurrence of mycotoxins in stored wheat samples $(n=179)$ in Ethiopia Legend:

$\mathrm{AFT}=$ Total aflatoxins, OTA $=$ Ochratoxin $\mathrm{A}, \mathrm{FUM}=$ Total Fumonisins, $\mathrm{DON}=$ Deoxynivalenol

Mycotoxins occur in foodstuffs, seldom alone, and they may have synergistic effects exacerbating the risk of adverse effects on human and animal health. Thus, grains consumed as staple diet could pose an increased risk to human [30]. Total aflatoxins have been classified as known carcinogens to humans [31], while fumonisin $\mathrm{B}_{1}$ and OTA have been classified as possibly carcinogenic substances to humans $[32,33]$. Several studies on experimental animals have revealed increased toxic effects through combined exposure to different mycotoxins.

In commercial milling operations of contaminated wheat into different flour streams, the grain mycotoxins will partition into the different flour streams. Compared to the original level in the whole grain, mycotoxins become concentrated in the nonendosperm streams (bran and germ), with a corresponding reduction in the endosperm flour stream [34]. Such redistribution of mycotoxins, however, cannot be achieved by the usual whole-grain flour production process accomplished using the local stone mills in Ethiopia. Rural households and a significant proportion of the urban ones consume wheat-based foods made from the whole grain. Although it is advisable to continue the consumption of wheat as a nutrient-dense and healthy whole grain product, appropriate 


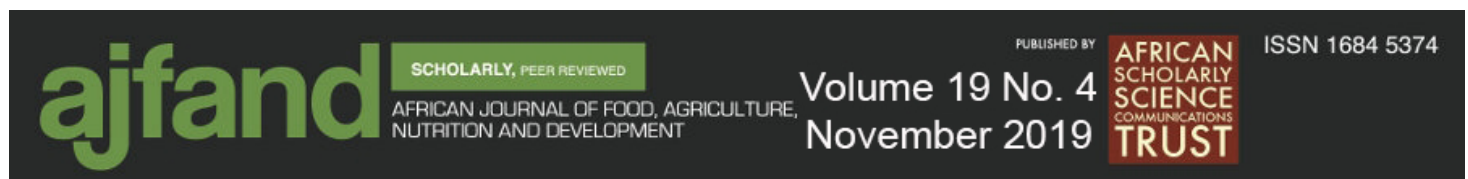

storage management is necessary to prevent mycotoxin formation, thereby minimizing dietary exposure to it.

Overall, the result indicates the need to put in place an appropriate mechanism to minimize mycotoxin related food safety problems in farm-stored wheat. Prevention is a better option for Ethiopia because the majority of wheat production is used for own food security by the smallholder farmer [6]. Hence, it is not practical to control mycotoxin contamination by enforcing maximum level standards in foods that do not pass through the marketing channels. Besides, the country is currently a net wheat importer [35] such that outlawing locally produced wheat by inspection alone can exacerbate shortage of the grain.

Long-term grain storage in hermetic bags is reported to be profitable in areas where grain price fluctuations are predominant [36]. Besides, hermetic bags can fit the practical needs of smallholder farmers in that bags are portable and occupy less space in the house where the grain is better monitored during storage [37]. Hermetic bags were found effective in preventing aflatoxin build-up and maintaining the initial grain quality during storage $[1,38]$.

\section{CONCLUSIONS}

The present investigation revealed the contamination of farm-stored wheat by four important mycotoxins. Regarding incidences, AFT was the most frequent contaminant among the four mycotoxins analyzed while DON was the least. Currently, there is no maximum level set for mycotoxins in cereals marketed in Ethiopia. Hence, the mycotoxin levels of wheat samples in the present study were evaluated using the maximum levels set by other countries. For instance, AFT concentrations of all wheat samples were below the maximum limit set by the FDA, while $49.2 \%$ of the samples were safe going by the EU maximum limit. The levels of OTA and DON (regulated in unprocessed cereals in the EU) were generally not high except for a few samples that had unacceptably high concentrations.

The authors recommend encouraging farmers to invest in improved grain storage technologies capable of protecting the grain from physical and biological factors that lead to mycotoxin formation. Hermetic bags are among the storage technologies capable of maintaining the initial quality of dried grains while practical to the needs of the smallholder farmers. 


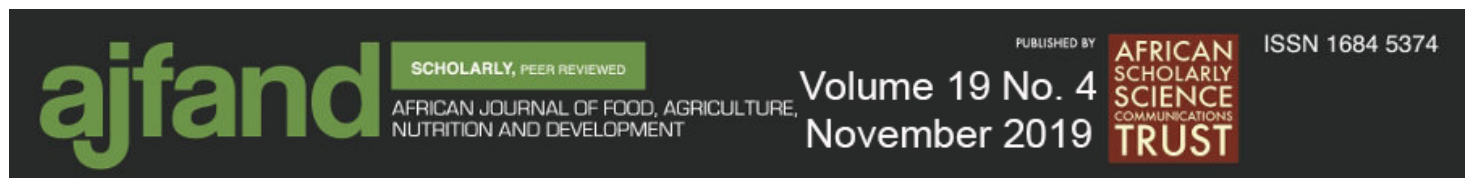

\section{ACKNOWLEDGEMENTS}

The authors thank the International Development Organization ACDI/VOCA (https://www.acdivoca.org/), Addis Ababa office, Ethiopia for providing in-kind mycotoxin testing facility and associated consumables (Sub-grant Number: FEED 2.1/A1-032/231/17), and for the facilitation of practical training delivered to the first author regarding the Standard Operating Procedure for Charm Sciences mycotoxin testing facilities.

The authors thank Bahir Dar Institute of Technology, Bahir Dar University, for the financial and logistic support granted for the research. The authors also thank the late Dr. Dereje Assefa, Mekelle University, Ethiopia, for his guidance on how to conduct this work.

Conflict of Interest: The authors have no conflict of interest to declare. 


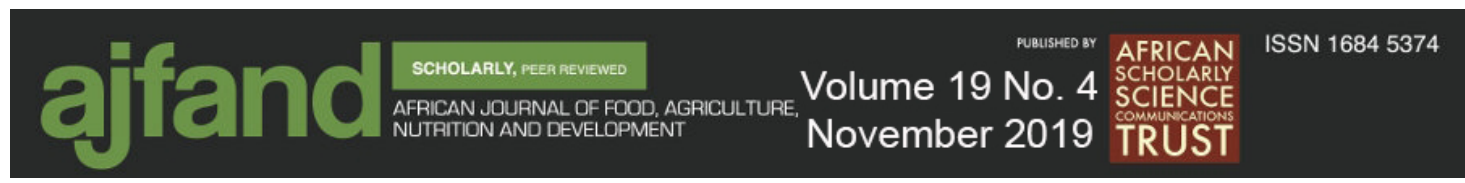

Table 1: Characteristics of Charm Sciences Lateral Flow test kits used in this study to quantify mycotoxins

\begin{tabular}{lcccc}
\hline $\begin{array}{l}\text { Channel } \\
\text { (Mycotoxin) }\end{array}$ & Test* & Dilution (matrix) & $\begin{array}{c}\text { Quantification } \\
\text { Range }\end{array}$ & $\begin{array}{c}\text { Limit of } \\
\text { Detection (LOD) }\end{array}$ \\
\hline Aflatoxin & AFQ-FAST (5MIN) Wheat & Diluted extract $(00)$ & $5-30(\mu \mathrm{g} / \mathrm{kg})$ & $2(\mu \mathrm{g} / \mathrm{kg})$ \\
& & $2^{\text {nd }}$ diluted extract $(01)$ & $20-100(\mu \mathrm{g} / \mathrm{kg})$ & - \\
Fumonisin & FUMQ-FAST5- Wheat & Diluted extract $(00)$ & $0.5-1.5(\mathrm{mg} / \mathrm{kg})$ & $0.25(\mathrm{mg} / \mathrm{kg})$ \\
& & $2^{\text {nd }}$ diluted extract $(01$ & $1-5(\mathrm{mg} / \mathrm{kg})$ & - \\
Ochratoxin A & OchraQ-Wheat & Diluted extract $(00)$ & $5-30(\mu \mathrm{g} / \mathrm{kg})$ & $2(\mu \mathrm{g} / \mathrm{kg})$ \\
& & $2^{\text {nd }}$ diluted extract $(01)$ & $20-150(\mu \mathrm{g} / \mathrm{kg})$ & - \\
Deoxynivalenol & DONQ2-Wheat & Diluted extract $(00)$ & $0.5-5(\mathrm{mg} / \mathrm{kg})$ & $0.1(\mathrm{mg} / \mathrm{kg})$ \\
& & $2^{\text {nd }}$ diluted extract $(01)$ & $5-30(\mathrm{mg} / \mathrm{kg})$ & - \\
\hline
\end{tabular}

* The test methods have been approved by USDA-GIPSA to quantify the four mycotoxins in wheat grain 


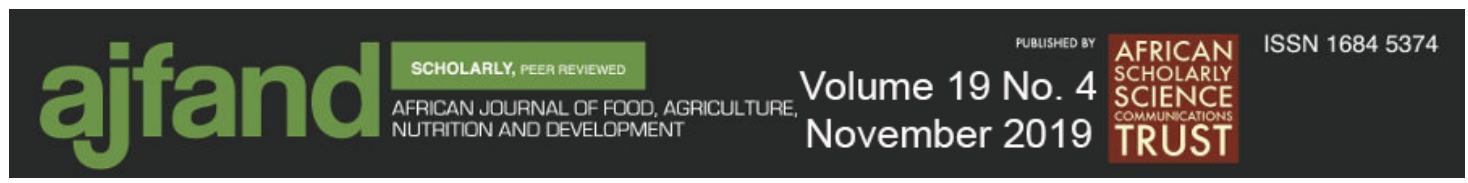

Table 2: Mean $( \pm$ SD) of water activity of wheat grains across districts and grain ages $(n=179)$

\begin{tabular}{|c|c|c|}
\hline Variable & $\mathbf{n}$ & $\begin{array}{c}\text { Water activity } \\
(\text { Mean } \pm \text { SD) }\end{array}$ \\
\hline \multicolumn{3}{|l|}{ District } \\
\hline Gedeb & 30 & $0.690 \pm 0.098^{\mathrm{a}}$ \\
\hline Hitosa & 30 & $0.724 \pm 0.128^{\mathrm{a}}$ \\
\hline Lemo & 30 & $0.716 \pm 0.121^{\mathrm{a}}$ \\
\hline Merawi & 29 & $0.537 \pm 0.083^{\mathrm{c}}$ \\
\hline Ofla & 30 & $0.608 \pm 0.078^{b}$ \\
\hline Wenberima & 30 & $0.607 \pm 0.062^{\mathrm{b}}$ \\
\hline$F_{5,173}$ & & 18.07 \\
\hline P-Value & & $<0.001$ \\
\hline \multicolumn{3}{|l|}{ Grain age } \\
\hline 3 months & 23 & $0.532 \pm 0.092^{\mathrm{c}}$ \\
\hline 7 months & 82 & $0.623 \pm 0.093^{\mathrm{b}}$ \\
\hline 8 months & 74 & $0.711 \pm 0.114^{\mathrm{a}}$ \\
\hline $\mathbf{F}_{1,177}$ & & 48.12 \\
\hline P-Value & & $<0.001$ \\
\hline
\end{tabular}

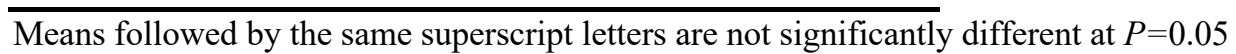




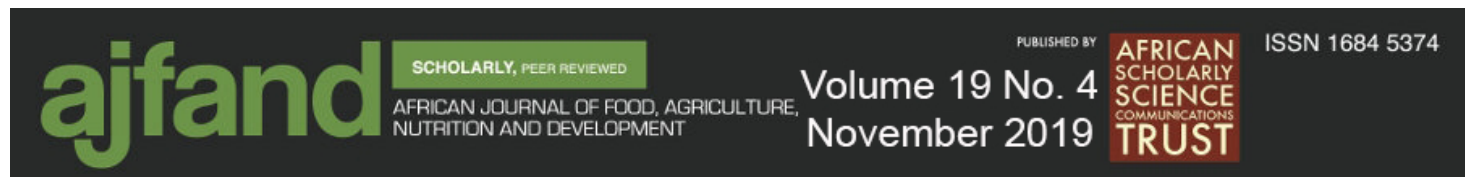

Table 3: Proportion of positive samples and levels of mycotoxins in wheat samples

\begin{tabular}{|c|c|c|c|c|c|c|}
\hline \multirow[t]{2}{*}{ Mycotoxin } & \multirow{2}{*}{$\begin{array}{l}\text { Proportion of } \\
\text { positive } \\
\text { samples }(\%) \\
(n=179)\end{array}$} & \multicolumn{3}{|c|}{$\begin{array}{l}\text { Mycotoxin level in } \\
\text { positive samples a }\end{array}$} & \multirow[t]{2}{*}{$\begin{array}{l}\text { Concentration } \\
\text { category }\end{array}$} & \multirow{2}{*}{$\begin{array}{c}\text { Number } \\
\text { of positive } \\
\text { samples per } \\
\text { category }^{b}\end{array}$} \\
\hline & & Range & Mean \pm SD & Median & & \\
\hline \multirow[t]{3}{*}{ Total Aflatoxins } & 60.3 & $2.5-16.7$ & $8.4 \pm 3.3$ & 9.2 & $<20$ & $108(100)$ \\
\hline & & & & & $<10$ & $74(68.5)$ \\
\hline & & & & & $<4$ & $17(15.7)$ \\
\hline \multirow[t]{3}{*}{ Ochratoxin A } & 20.1 & $2.5-148.8$ & $12.1 \pm 32.0$ & 3.6 & $<5$ & $28(77.8)$ \\
\hline & & & & & $<10$ & 33(91.7) \\
\hline & & & & & $<100$ & 34(94.4) \\
\hline Total & 16.2 & $0.33-0.71$ & $0.45 \pm 0.08$ & 0.42 & 1 & $20(100)$ \\
\hline \multicolumn{7}{|l|}{ Fumonisins } \\
\hline \multirow[t]{2}{*}{ Deoxynivalenol } & 9.5 & $0.35-1.14$ & $0.64 \pm 0.25$ & 0.63 & $<0.75$ & $11(64.7)$ \\
\hline & & & & & $<1.0$ & $15(88.2)$ \\
\hline
\end{tabular}

${ }^{\mathrm{a}} \mu \mathrm{g} / \mathrm{kg}$ for AFT and OTA, and $\mathrm{mg} / \mathrm{kg}$ for FUM and DON

${ }^{b}$ Numbers in parenthesis are percentages of positive samples in the concentration category regardless of district 


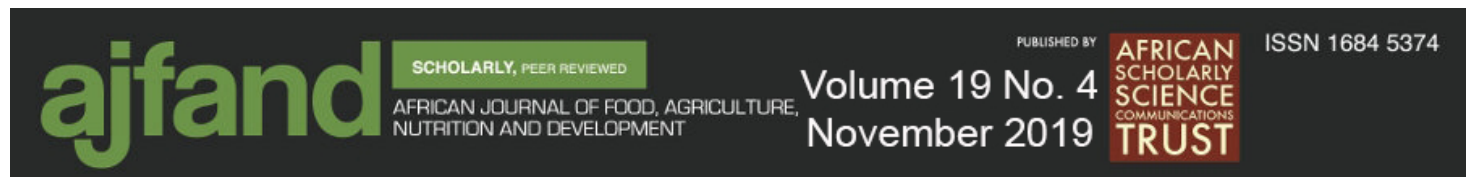

Table 4: Fisher exact test between the proportion of mycotoxin positive samples and age of grain after harvest $(n=179)$

\begin{tabular}{lccccc}
\hline $\begin{array}{c}\text { Grain age } \\
\text { (months) }\end{array}$ & $\mathbf{n}$ & \multicolumn{4}{c}{ Proportion of positive samples (\%) } \\
\cline { 2 - 6 } & 23 & $\begin{array}{c}\text { Total } \\
\text { Aflatoxins }\end{array}$ & Ochratoxin A & $\begin{array}{c}\text { Total } \\
\text { Fumonisins }\end{array}$ & Deoxynivalenol \\
\hline 3 & $21.7^{\mathrm{a}}$ & 17.4 & 17.4 & 13.0 \\
7 & 82 & $73.2^{\mathrm{b}}$ & 19.5 & 18.3 & 12.2 \\
8 & 74 & $58.1^{\mathrm{b}}$ & 21.6 & 13.5 & 5.4 \\
& $\boldsymbol{P}$-value & $<\mathbf{0 . 0 1}$ & $\mathbf{0 . 9 0}$ & $\mathbf{0 . 7 5}$ & $\mathbf{0 . 2 5}$ \\
\hline
\end{tabular}

Means followed by the same superscript letters are not significantly different at $P=0.05$ 


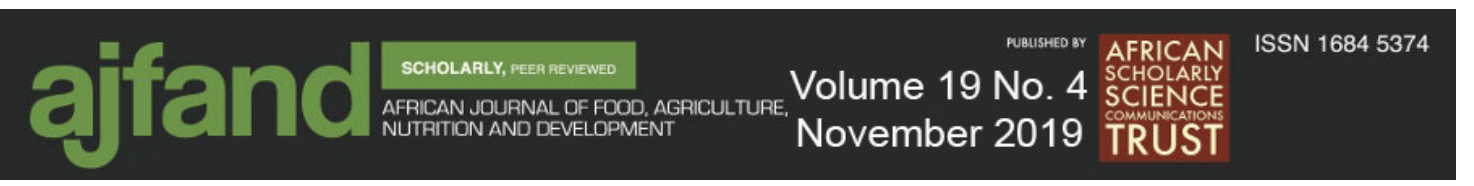

Table 5: Incidence and levels of mycotoxins in wheat samples from each district

\begin{tabular}{|c|c|c|c|c|c|c|c|c|c|c|c|c|c|c|}
\hline \multirow[b]{3}{*}{ District } & \multirow[b]{3}{*}{$\mathbf{n}$} & \multirow[b]{3}{*}{$\begin{array}{l}\text { Grain age } \\
\text { (months) }\end{array}$} & \multicolumn{12}{|c|}{ Mycotoxin incidences and level in positive samples* } \\
\hline & & & \multicolumn{3}{|c|}{$\begin{array}{c}\text { Total aflatoxins } \\
(\mu \mathrm{g} / \mathrm{kg})\end{array}$} & \multicolumn{3}{|c|}{$\begin{array}{c}\text { Ochratoxin A } \\
(\mu \mathrm{g} / \mathrm{kg})\end{array}$} & \multicolumn{3}{|c|}{$\begin{array}{c}\text { Total Fumonisins } \\
(\mathrm{mg} / \mathrm{kg})\end{array}$} & \multicolumn{3}{|c|}{$\begin{array}{c}\text { Deoxynivalenol } \\
(\mathrm{mg} / \mathrm{kg})\end{array}$} \\
\hline & & & 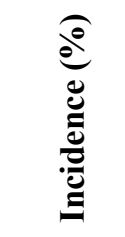 & 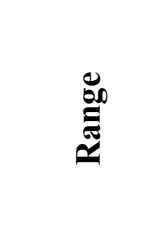 & 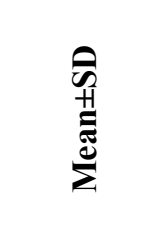 & 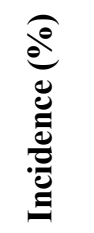 & 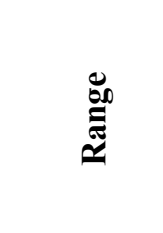 & 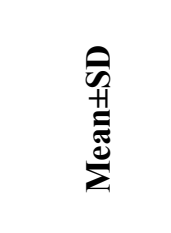 & 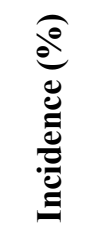 & 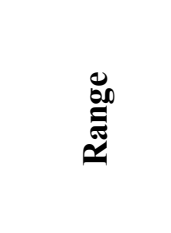 & 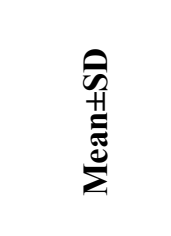 & 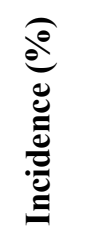 & 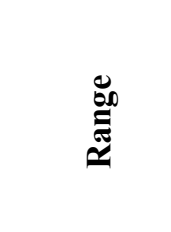 & 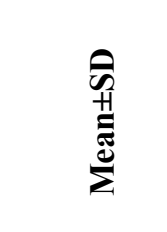 \\
\hline Gedeb & 30 & 8 & $76.7^{\mathrm{a}}$ & $2.5-13.4$ & $8.5 \pm 3.9$ & 20.0 & $2.1-148.2$ & $27.1 \pm 59.3$ & $0.0^{\mathrm{a}}$ & $0.0-0.0$ & $0.0 \pm 0.0$ & 0.0 & $0.0-0.0$ & $0.0 \pm 0.0$ \\
\hline Hitosa & 30 & 8 & $53.3^{\mathrm{ab}}$ & $2.5-13.5$ & $7.5 \pm 3.9$ & 20.0 & $2.2-32.8$ & $8.9 \pm 12.0$ & $13.3^{\mathrm{ab}}$ & $0.42-0.46$ & $0.44 \pm 0.02$ & 10.0 & $0.42-1.11$ & $0.82 \pm 0.36$ \\
\hline Lemo & 30 & 7.5 & $26.7^{\mathrm{bc}}$ & $2.5-10.7$ & $5.1 \pm 3.2$ & 23.3 & $2.1-4.7$ & $2.9 \pm 1.0$ & $33.3^{\mathrm{b}}$ & $0.36-0.47$ & $0.41 \pm 0.03$ & 6.7 & $0.47-0.77$ & $0.62 \pm 0.21$ \\
\hline Merawi & 29 & 3.8 & $24.1^{\mathrm{c}}$ & $2.5-7.0$ & $4.7 \pm 2.1$ & 13.3 & $2.1-4.9$ & $3.0 \pm 1.3$ & $17.2^{\mathrm{ab}}$ & $0.42-0.71$ & $0.53 \pm 0.11$ & 10.3 & $0.35-0.45$ & $0.41 \pm 0.05$ \\
\hline Ofla & 30 & 7 & $80.0^{\mathrm{a}}$ & $2.5-16.7$ & $10.7 \pm 2.0$ & 10.0 & $2.3-132.8$ & $46.4 \pm 74.8$ & $0.0^{\mathrm{a}}$ & $0.0-0.0$ & $0.0 \pm 0.0$ & 3.3 & 0.62 & 0.62 \\
\hline Wenberima & 30 & 7 & $100.0^{\mathrm{d}}$ & 5.9-13.1 & $8.9 \pm 1.6$ & 33.3 & $3.2-6.0$ & $4.5 \pm 0.9$ & $33.3^{\mathrm{b}}$ & $0.33-0.62$ & $0.44 \pm 0.09$ & 26.7 & $0.42-1.14$ & $0.67 \pm 0.24$ \\
\hline$P$-value & & & $<0.01$ & & & 0.32 & & & $<0.01$ & & & 0.34 & & \\
\hline
\end{tabular}




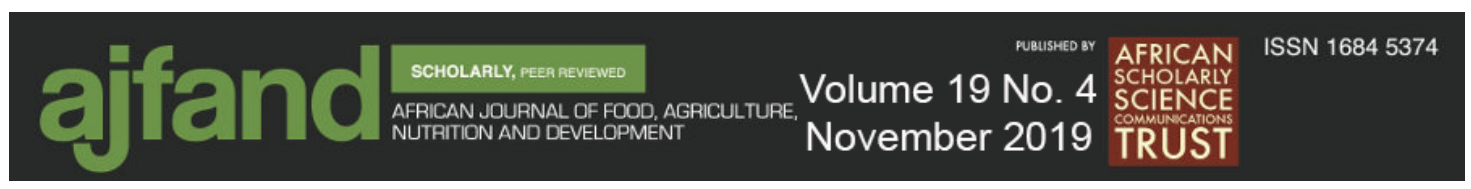

\section{REFERENCES}

1. Kalsa K, Subramanyam B, Demissie G, Mahroof R, Worku A and N Gabbiye Evaluation of postharvest preservation strategies for stored wheat seed in Ethiopia. $J$ Stored Prod Res 2019;81: 53-61.

2. CSA. Central Statistical Agency of the Federal Democratic Republic of Ethiopia. Area and production of major crops: Volume one. Addis Ababa, Ethiopia, 2018.

3. Workicho A, Belachew T, Feyissa G T, Wondafrash B, Lachat C, Verstraeten R and $\mathbf{P}$ Kolsteren Household dietary diversity and animal source food consumption in Ethiopia: evidence from the 2011 welfare monitoring survey. BMC public health 2016; 16: 1192 .

4. FAO. United Nations Food and Agriculture Organization. Food supply - crops primary equivalent. FAOSTAT database, 2018. Available at: http://www.fao.org/faostat/en/\#data/CC. Accessed: 05-Apr-2019.

5. Shiferaw B, Kassie M, Jaleta $M$ and $\mathbf{C}$ Yirga Adoption of improved wheat varieties and impacts on household food security in Ethiopia. Food Policy 2014; 44: 272-284.

6. CSA. Central Statistical Agency of the Federal Democratic Republic of Ethiopia. Crop and livestock product utilization: Volume 7. Addis Ababa, Ethiopia, 2018.

7. Hengsdijk $\mathbf{H}$ and WJ De Boer Post-harvest management and post-harvest losses of cereals in Ethiopia. Food Secur 2017; 9: 945-958.

8. Bradford K J, Dahal P, Van Asbrouck J, Kunusoth K, Bello P, Thompson J and F Wu The dry chain: Reducing postharvest losses and improving food safety in humid climates. Trends Food Sci Technol 2018; 71: 84-93.

9. Rodriguez-Carrasco Y, Fattore M, Albrizio S, Berrada H and J Mañes Occurrence of Fusarium mycotoxins and their dietary intake through beer consumption by the European population. Food Chem 2015; 178: 149-155.

10. Turner PC, Nikiema $\mathbf{P}$ and CPWild Fumonisin contamination of food: progress in development of biomarkers to better assess human health risks. Mutat Res Genet Toxicol Environ Mutagen 1999; 443: 81-93.

11. Miller JD Fungi and mycotoxins in grain: implications for stored product research. $J$ Stored Prod Res 1995; 31: 1-16.

12. Mashinini K and MF Dutton The incidence of fungi and mycotoxins in South Africa wheat and wheat-based products. J Environ Sci Health B 2006; 41(3): 285-296.

13. Ayalew A, Fehrmann H, Lepschy $\mathbf{J}$, Beck $\mathbf{R}$ and $\mathbf{D}$ Abate Natural occurrence of mycotoxins in staple cereals from Ethiopia. Mycopathologia 2006; 162: 57-63. 


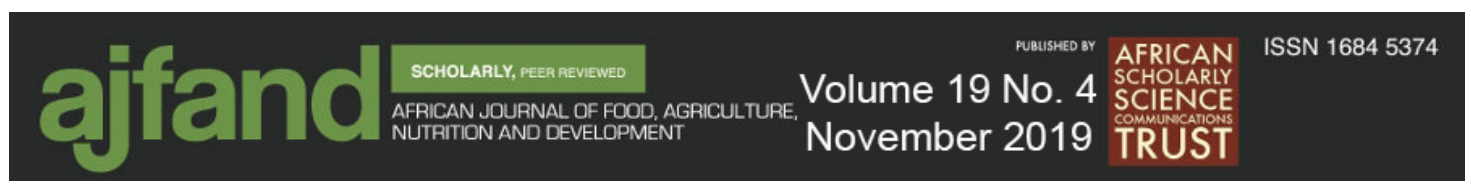

14. Chilaka CA, De Boevre M, Atanda OO and S De Saeger The status of Fusarium mycotoxins in sub-Saharan Africa: A review of emerging trends and post-harvest mitigation strategies towards food control. Toxins 2017; 9: 19.

15. Mason RL, Gunst RF and JL Hess Statistical Design and Analysis of Experiments: With Applications to Engineering and Science, $2^{\text {nd }}$ Edition. John Wiley $\&$ Sons, Hoboken, USA. 2003:47.

16. Boxall RA, Brice JR, Taylor SJ and RD Bancroft Technology and Management of Storage. In: Golob G, Farrell and JE Orchard (Eds). Crop Post-Harvest: Science and Technology, Volume 1- Principles and Practice. Oxford, UK: Blackwell Science Publishing, 2002:142-232.

17. Fontana AJJ Measurement of water activity, moisture sorption isotherms, and moisture content of foods. In: Barbosa-Canovas GV, Fontana AJJ, Schmidt SJ and TP Labuza (Eds). Water Activity in foods-Fundamentals and applications. Iowa, USA: IFT Press-Blackwell Publishing, 2007:155-171.

18. Mendoza JR, Rodas A, Oliva A, Sabillon L, Colmenares A, Clarke J, HallenAdams HE Campabadal C and A Bianchini Safety and quality assessment of smallholder farmers' maize in the western highlands of Guatemala. J Food Prot2018; 81(5): $776-784$.

19. Nielsen LK, Cook DJ, Edwards SG and RV Ray The prevalence and impact of Fusarium head blight pathogens and mycotoxins on malting barley quality in UK. Int $J$ Food Microbiol 2014; 179: 38-49.

20. Zar JH A fast and efficient algorithm for the Fisher exact test. Behav Res Methods 1987; 19 (4): 413-414.

21. Anonymous SigmaPlot version 12.5. Systat Software, Inc., San Jose, California, USA, 2013.

22. Kumar D and K Prasanta Reducing postharvest losses during storage of grain crops to strengthen food security in developing countries. Foods 2017; 6: 8.

23. Worku AF, Abera M, Kalsa KK, Sateesh N, Workneh SF and NG Habtu Occurrence of mycotoxins in stored maize in Ethiopia. Ethiop. J. Agric. Sci. 2019; 29(2): 31-43.

24. NGFA. National Grain and Feed Association. FDA mycotoxin regulatory guidance: A guide for grain elevators, feed manufacturers, grain processors and exporters.

Washington DC, USA, 2011.

25. European Union. Official Journal of the European Union.Commission regulation (EC) No 1881/2006 of 19 December 2006 setting maximum levels for certain contaminants in foodstuffs. Available at: http://data.europa.eu/eli/reg/2006/1881/oj. Accessed: 03Jan-2019. 


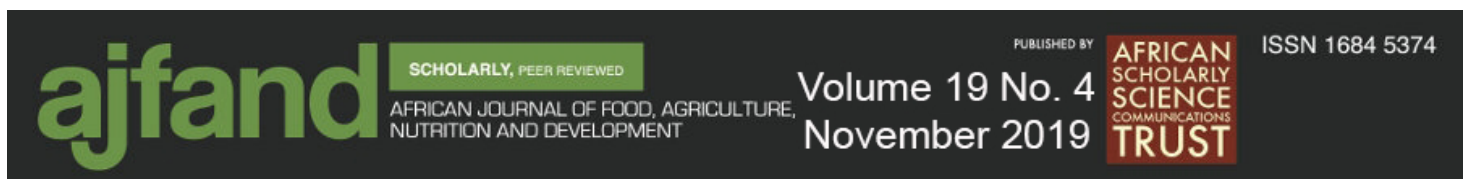

26. Kotir JH Climate change and variability in Sub-Saharan Africa: a review of current and future trends and impacts on agriculture and food security. Environ Dev Sustain 2011; 13(3): 587-605.

27. Tirado MC, Clarke R, Jaykus LA, McQuatters-Gollop A and JM Frank Climate change and food safety: A review.Food Res Int 2010; 43(7):1745-1765.

28. Munkvold GP and AE Desjardins Fumonisins in maize: can we reduce their occurrence? Plant Dis 1997; 81(6): 556-565.

29. Smith MC, Madec S, Coton $\mathbf{E}$ and $\mathbf{N}$ Hymery Natural co-occurrence of mycotoxins in foods and feeds and their in vitro combined toxicological effects. Toxins 2016; 8(4): 94.

30. Hove M, Van Poucke C, Njumbe-Ediage E, Nyanga LK and S De Saeger Review on the natural co-occurrence of $\mathrm{AFB}_{1}$ and $\mathrm{FB}_{1}$ in maize and the combined toxicity of $\mathrm{AFB}_{1}$ and $\mathrm{FB}_{1}$. Food Control 2016; 59: 675-682.

31. IARC. International Agency for Research on Cancer. Chemical agents and related occupations: a review of human carcinogens. Lyon, France, 2012.

32. IARC. International Agency for Research on Cancer. Some naturally occurring substances: food items and constituents, heterocyclic aromatic amines and mycotoxins, vol. 56. Lyon, France, 1993.

33. IARC. International Agency for Research on Cancer. Some traditional herbal medicines, some mycotoxins, naphthalene and styrene. Lyon, France, 2002.

34. Schaarschmidt $\mathbf{S}$ and $\mathbf{C}$ Fauhl-Hassek The fate of mycotoxins during the processing of wheat for human consumption. Compr Rev Food Sci Food Saf2018; 17(3): 556-593.

35. Dessalegn T, Solomon T, Kristos TG, Solomon A, Shure S, Yazzie C, Subramanyam B, Roberts KA, Abay F and R Mahroof Post-harvest wheat losses in Africa: An Ethiopian case study. In: Langridge P (Ed). Achieving sustainable cultivation of wheat Volume 2: Cultivation techniques. Cambridge, UK: Burleigh Dodds Science Publishing, 2017: 85-104.

36. Kotu BH, Abass AB, Hoeschle-Zeledon I, Mbwambo $\mathrm{H}$ and M Mateete BekundaExploring the profitability of improved storage technologies and their potential impacts on food security and income of smallholder farm households in Tanzania. $J$ Stored Prod Res 2019; 82: 98-109.

37. Manandhar A, Milindi $\mathbf{P}$ and A Shah An overview of the post-harvest grain storage practices of smallholder farmers in developing countries. Agriculture 2018; 8: 57

38. Ng'ang'a J, Mutungi $\mathbf{C}$, Imathiu $\mathbf{S}$ and $\mathbf{H}$ AffognonEffect of triple-layer hermetic bagging on mould infection and aflatoxin contamination of maize during multi-month on-farm storage in Kenya. J Stored Prod Res2016; 69: 119-128. 